\title{
Tunable Structures and Properties of Electrospun Regenerated Silk Fibroin Mats Annealed in Water Vapor at Different Times and Temperatures
}

\author{
Xiangyu Huang, ${ }^{1}$ Suna Fan, ${ }^{1}$ Alhadi Ibrahim Mohammed Altayp, ${ }^{1}$ Yaopeng Zhang, \\ Huili Shao, ${ }^{1}$ Xuechao Hu, ${ }^{1}$ Minkai Xie, ${ }^{2}$ and Yuemin $\mathrm{Xu}^{2}$ \\ ${ }^{1}$ State Key Laboratory for Modification of Chemical Fibers and Polymer Materials, College of Materials Science and Engineering, \\ Donghua University, Shanghai 201620, China \\ ${ }^{2}$ Department of Urology, Shanghai Jiaotong University Affiliated Sixth People’s Hospital, Shanghai 200233, China
}

Correspondence should be addressed to Yaopeng Zhang; zyp@dhu.edu.cn and Yuemin Xu; xuyuemin@263.com

Received 26 February 2014; Accepted 12 April 2014; Published 5 May 2014

Academic Editor: Huarong Nie

Copyright (C) 2014 Xiangyu Huang et al. This is an open access article distributed under the Creative Commons Attribution License, which permits unrestricted use, distribution, and reproduction in any medium, provided the original work is properly cited.

\begin{abstract}
Regenerated silk fibroin (SF) mats were fabricated using electrospinning technique, followed by mild water vapor annealing to effectively tune the structures and improve the mechanical properties of the mats at different annealing times and temperatures. The breaking strength and the breaking energy of the mats treated with water vapor at $65^{\circ} \mathrm{C}$ for $12 \mathrm{~h}$ reached $6.0 \mathrm{MPa}$ and $171.7 \mathrm{~J} / \mathrm{kg}$, respectively. The conformational transition of the SF mats was significantly influenced by the treating temperature, while the influence of time was comparatively limited. The influence is consistent with the time-temperature equivalent principle and would be helpful for the preparation of water-vapor-annealed silk-based biomaterials for various applications.
\end{abstract}

\section{Introduction}

Silk fibroin (SF), the main component of natural silks from Bombyx mori silkworms, has contributed to the outstanding mechanical properties, excellent biocompatibility, and controllable biodegradability of silks [1]. Recently, many SFbased materials have been developed in different forms for biomedical applications, such as scaffolds, hydrogels, porous sponges, tubes, microspheres, and fibers [2-10]. In these forms of SF, electrospun SF mats exhibit similar morphological structure to the native extracellular matrix (ECM), which may greatly promote the cell attachment and proliferation on this material $[11,12]$.

Before the electrospun SF mats are applied in tissue engineering, they always require certain types of posttreatment to enhance their mechanical properties and stability in water. Most of the reported posttreatment methods are based on the chemical agents, especially the aqueous alcoholic solutions $[13,14]$. However, the organic solvents may cause potential negative effects on human bodies. The soaking process may also lead to the loss of embedded drugs, thereby limiting the applications of SF mats in drug-delivery fields [15]. Recently, a posttreatment method using water vapor annealing to induce the conformational transition in SF has been investigated due to its mild processing conditions and elimination of organic solvents. Min et al. [16] proved the mild characteristic of water vapor treatment through investigating cell behavior on water-vapor-treated SF nanofibers. Jeong et al. [17] confirmed that water vapor could successfully stabilize the SF matrices as alcohol vapor. However, the results of water vapor treatment may significantly depend on the treating time and the temperature. Therefore, in order to control the structures and properties of SF via water vapor annealing, it is necessary to investigate the detailed influence of temperature and time on SF. Hu et al. reported a method of temperature-controlled water vapor annealing to control the structures and properties of SF films [18]. However, the detailed influences of annealing time and temperature on SF mats are rarely reported. Moreover, the average diameter of the electrospun fibers is much smaller than the thickness of 
films, so that the influences of posttreatment process on the mats may be significantly different from those on the films.

In this study, we provide an effective and easy-conducting approach to fabricate electrospun regenerated SF mats with tunable structures through water vapor annealing at different times and temperatures. Improved mechanical properties are desired to be achieved for further biomedical applications.

\section{Experimental}

2.1. Materials. B. mori cocoons produced in Zhejiang Province, China, were used as raw material to extract SF. Analytical-grade sodium carbonate $\left(\mathrm{Na}_{2} \mathrm{CO}_{3}\right)$ and lithium bromide ( $\mathrm{LiBr}$ ) were obtained from Sinopharm Chemical Reagent Co., Ltd. (Shanghai, China) and Zhongli Industrial Co., Ltd. (Shanghai, China), respectively. Cellulose semipermeable membranes with a molecular weight cutoff of $14000 \pm$ 2000 D were purchased from Yuanju Co., Ltd. (Shanghai, China).

2.2. Preparation of Silk Fibroin and Electrospun Mats. The B. mori cocoons were boiled twice in $0.5 \mathrm{wt} \% \mathrm{Na}_{2} \mathrm{CO}_{3}$ solution to remove sericin. Degummed silks were then dissolved in 9.0 $\mathrm{M} \mathrm{LiBr}$ aqueous solution at $40^{\circ} \mathrm{C}$ for $2 \mathrm{~h}$ and further dialyzed in deionized water at $10^{\circ} \mathrm{C}$ for 3 days according to the established procedures [19]. Ultimately, a purified $33 \mathrm{wt} \%$ SF solution was obtained through concentrating at $10^{\circ} \mathrm{C}$.

The SF mats were fabricated by electrospinning using the purified $33 \mathrm{wt} \%$ SF solution and were randomly collected on a grounded collector with a spinneret-to-collector distance of $10 \mathrm{~cm}$. During electrospinning, a high voltage of $20 \mathrm{kV}$ was applied and a flow rate of spinning dope was maintained at $1.2 \mathrm{~mL} / \mathrm{h}$. The details of this process can be found in our previous literature [20].

2.3. Water Vapor Annealing on SF Mats. A constant temperature and humidity chamber (HCP 108, Memmert GmbH + Co. KG, Germany) was used in the posttreatment process. Relative humidity $(\mathrm{RH})$ in the chamber was fixed at $90 \pm 1 \%$. In the temperature-controlled series, samples were treated with water vapor for $3 \mathrm{~h}$ at different temperatures: 45, 55, 65, and $75^{\circ} \mathrm{C}$. In the time-controlled series, samples were treated with water vapor at $65^{\circ} \mathrm{C}$ for different times: $0.5,1,3,6,9$, $12,15,18$, and $24 \mathrm{~h}$. After posttreatment, samples were dried in a sealed container with desiccant for $48 \mathrm{~h}$ before further characterization.

2.4. Characterization. The morphology of the SF mats was examined by scanning electron microscopy (SEM; JSM5600LV, JEOL, Japan). Diameters of the electrospun fibers were measured directly from their SEM images using Image Tool software based on at least 100 fibers.

The secondary structure of the electrospun fibers was characterized by a Raman spectrometer (LabRAM-1 B, Dilor, France) at a $1 \mathrm{~cm}^{-1}$ resolution. All samples were irradiated by a He-Ne laser with a wavelength of $632.8 \mathrm{~nm}$. Spectra were recorded in the range of $900-1800 \mathrm{~cm}^{-1}$.
Wide angle X-ray diffraction (WAXD) patterns were obtained at the BL15U1 beamline in Shanghai Synchrotron Radiation Facility (SSRF) at a wavelength of $0.07746 \mathrm{~nm}$. The sample-to-detector distance was calibrated using lanthanum hexaboride $\left(\mathrm{LaB}_{6}\right)$ as a standard to $187 \mathrm{~mm}$. Each specimen was exposed for $30 \mathrm{~s}$ and the corresponding background was recorded simultaneously. Data analysis was carried out by FIT2D software. Then a method reported previously was applied to calculate the crystallinity of the SF mats according to the diffractograms [21].

An Instron 5969 material testing instrument (Instron Co., USA) was applied to investigate the mechanical properties of the mats at $25 \pm 5^{\circ} \mathrm{C}$ and $50 \pm 5 \% \mathrm{RH}$. Thickness of the samples was tested by a $\mathrm{CH}-1-\mathrm{S}$ thickness gauge (Shanghai Liuling Instruments Co., China). All samples were cut into $5 \mathrm{~mm} \times$ $40 \mathrm{~mm}$ pieces for tensile test, which was conducted with an extension rate of $1 \mathrm{~mm} / \mathrm{min}$ and a gauge length of $20 \mathrm{~mm}$. At least 10 specimens were tested for each mat sample.

\section{Results and Discussion}

3.1. Morphology and Nanostructure of SF Mats. Figure 1 shows typical morphologies and diameter distribution histograms of the electrospun SF mats which were obtained by water vapor annealing at different conditions. As-spun mat was also shown in the figure for comparison. All watervapor-annealed samples and the as-spun sample present smooth surface morphologies. When compared with the alcohol-treated or postdrawn SF mats with rough surface $[20,22]$, the water-vapor-annealed samples with smooth surface show obvious advantages. This suggests that the water vapor annealing is quite a mild posttreating method which would not cause severe damages to the fiber surface. And the diameter distribution histograms show that the diameters of fibers increase with the temperature. This is probably attributed to the significant swelling of SF fibers in water vapor during annealing.

3.2. Secondary Structures of SF Mats. The secondary structure transition of the SF fibers occurs in the water vapor annealing process. Figure 2 shows the Raman spectra of the SF mats posttreated at different times and temperatures. The assignments of the major bands in the spectra were based on literatures $[23,24]$. Spectra of the as-spun fibers exhibit obvious bands relate to $\alpha$-helix $\left(1103 \mathrm{~cm}^{-1}\right)$, random coil $\left(1251,946 \mathrm{~cm}^{-1}\right)$, and $\beta$-turn $\left(1675 \mathrm{~cm}^{-1}\right)$, which are somehow obscure in the posttreated samples. In addition, intense bands at $1666 \mathrm{~cm}^{-1}, 1230 \mathrm{~cm}^{-1}$, and $1085 \mathrm{~cm}^{-1}$ which correspond to $\beta$-sheet conformation are observed in the spectra of the posttreated fibers. The varied intensities of the characteristic peaks suggest that the time and temperature definitely affect the structural transition of SF mats in different degrees.

To further investigate the relationships between secondary structure of the SF mats and annealing condition, we conducted the quantitative analysis in amide I region of Raman spectra. As shown in Figure 3, with prolonged time or raised temperature, the $\beta$-sheet content significantly increases accompanied with decreased contents of $\alpha$-helix 


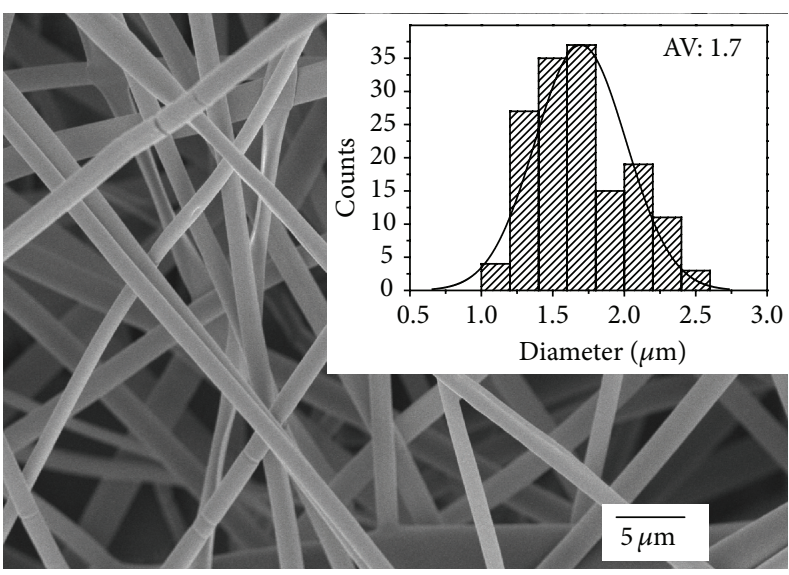

(a)

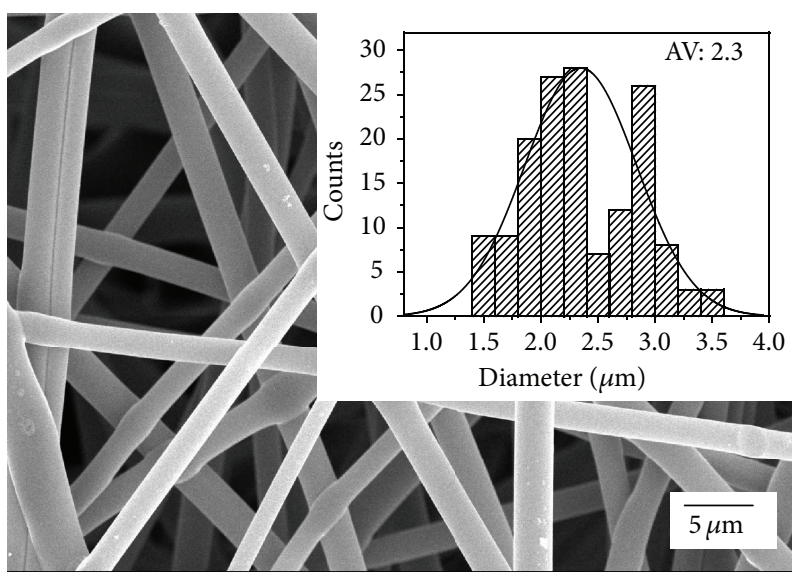

(c)

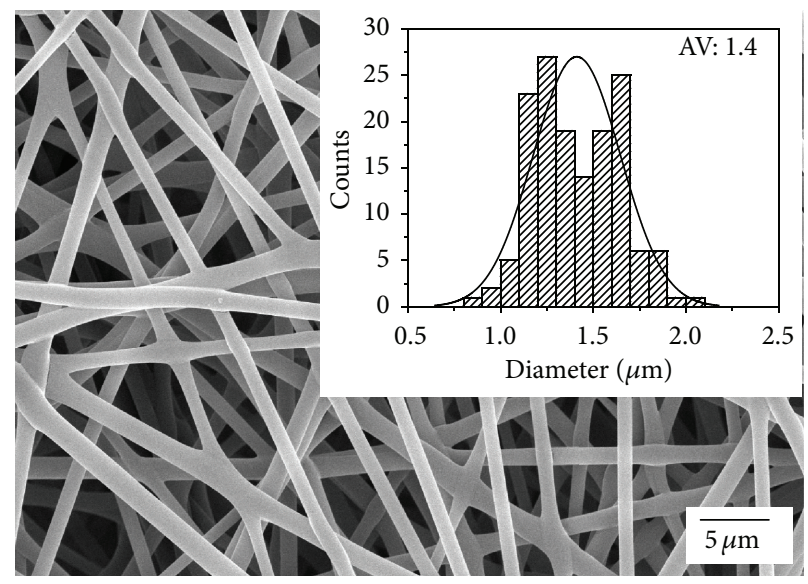

(b)
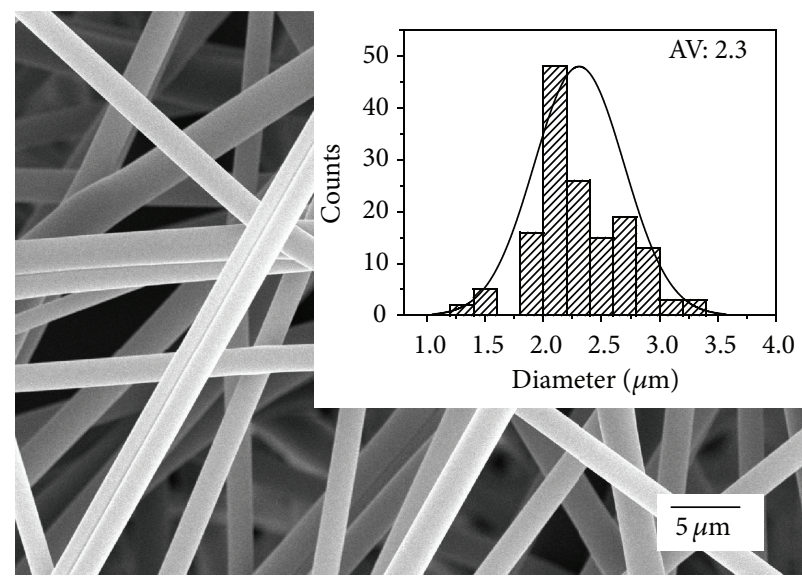

(d)

FIGURE 1: SEM images and diameter distribution histograms of water-vapor-annealed electrospun SF mats under different conditions: (a) as-spun; (b) $55^{\circ} \mathrm{C}-3 \mathrm{~h}$; (c) $65^{\circ} \mathrm{C}-3 \mathrm{~h}$; and (d) $65^{\circ} \mathrm{C}-9 \mathrm{~h}$.

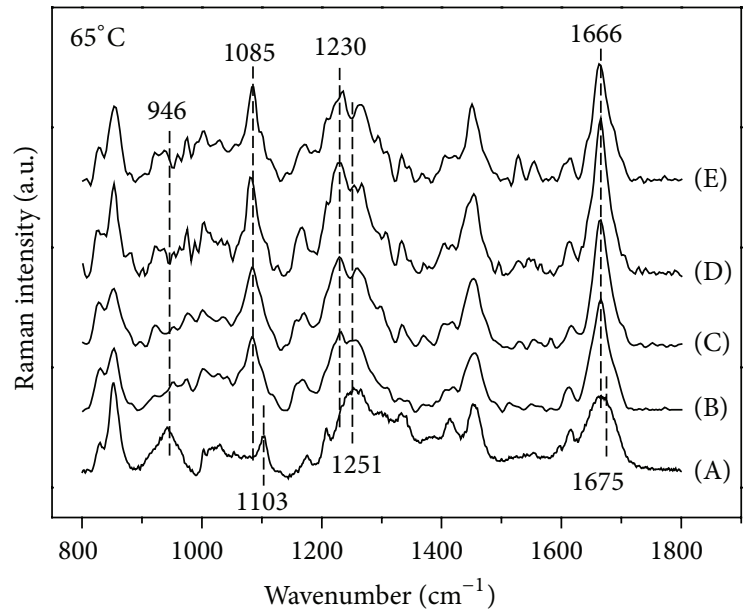

(a)

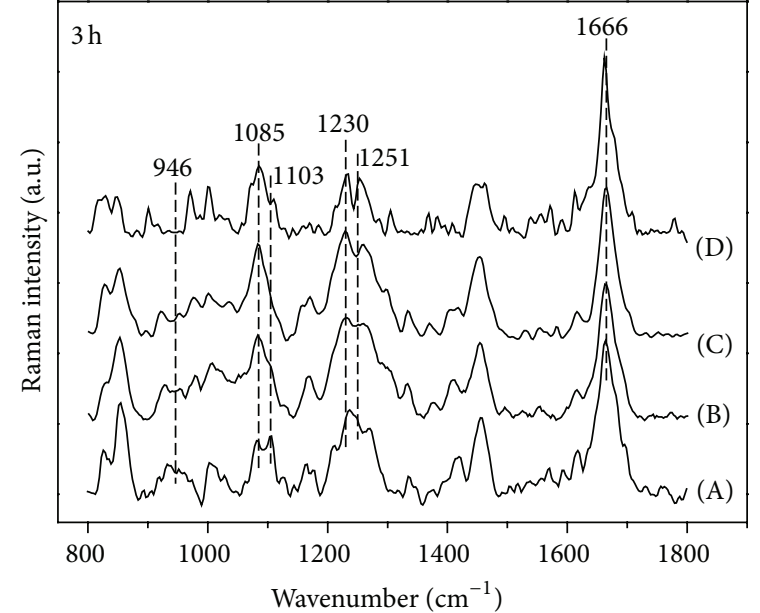

(b)

Figure 2: Raman spectra of electrospun SF fibers: (a) samples treated with water vapor at $65^{\circ} \mathrm{C}$ for different times: (A) as-spun, (B) $0.5 \mathrm{~h}$, (C) $3 \mathrm{~h},(\mathrm{D}) 9 \mathrm{~h}$, and (E) $24 \mathrm{~h}$; (b) samples treated with water vapor for $3 \mathrm{~h}$ at different temperatures: (A) $45^{\circ} \mathrm{C}$, (B) $55^{\circ} \mathrm{C}$, (C) $65^{\circ} \mathrm{C}$, and (D) $75^{\circ} \mathrm{C}$. 


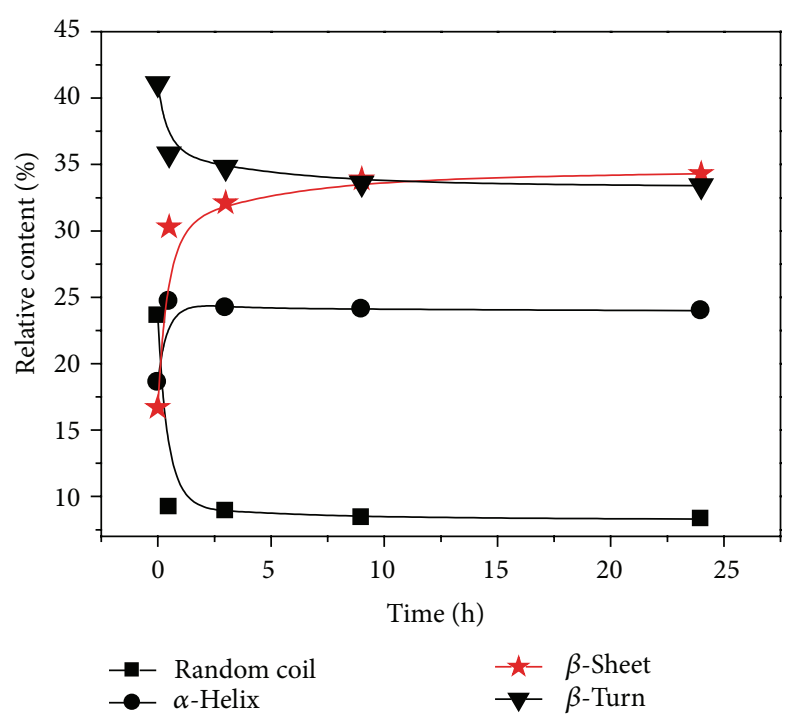

(a)

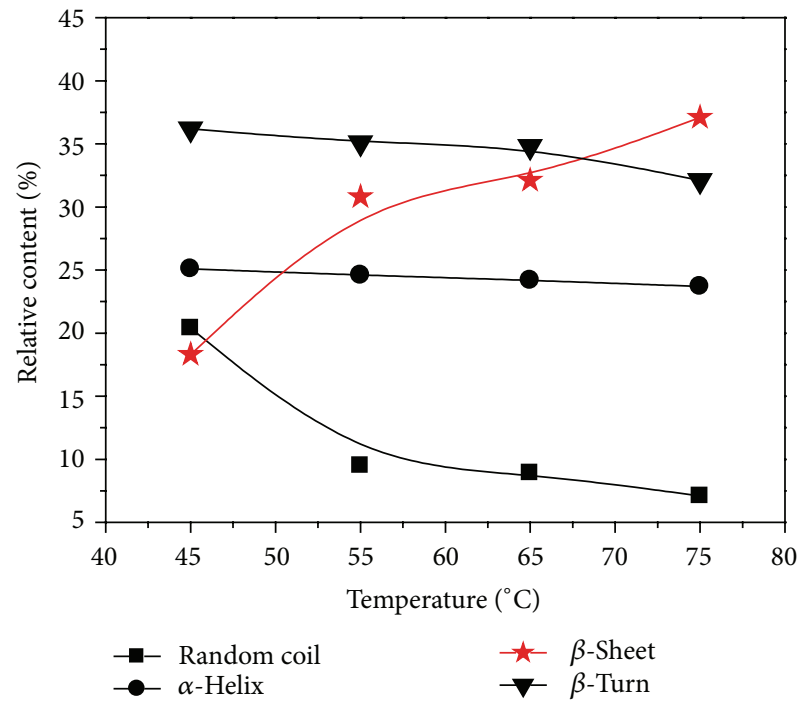

(b)

FIGURE 3: Quantitative analysis of the secondary structure components of electrospun SF fibers treated with water vapor at different conditions: (a) annealed at $65^{\circ} \mathrm{C}$ for different times; (b) annealed for $3 \mathrm{~h}$ at different temperatures.

(time $>0.5 \mathrm{~h}$ ), random coil, and $\beta$-turn conformation. This suggests that SF mats with desired secondary structures can be achieved through controlling a single variable of either time or temperature during water vapor annealing. The SF mats annealed at $75^{\circ} \mathrm{C}$ for $3 \mathrm{~h}$ (37.1\%) show an even higher $\beta$-sheet content than the mats treated at $65^{\circ} \mathrm{C}$ for $24 \mathrm{~h}$ (34.3\%). This indicates that the increase of temperature may be more effective than time in inducing the conformation transition of SF. Apart from high temperature, water molecule is another indispensable factor in the formation of $\beta$-sheets. As proved by Hu et al. [25], the water-silk structure possesses a lower glass transition temperature than that of the pure dry silk. Therefore, during the water vapor annealing process, the high content of free water molecules may weaken the original intermolecular bonding force within SF and decrease the required energy for movements of amino acids [26]. Moreover, the high ambient temperature could provide more energy for the molecular movements. As a result, the hightemperature water vapor annealing successfully induces the conformational transition of SF. Mo et al. [27] also found that the formation of $\beta$-sheets in SF relates to the dissociation of hydrogen bonds between water and peptides and reformation of stronger hydrogen bonds between peptides themselves. Accordingly, we may be able to control the microstructure of SF materials accurately in a high-humidity environment by simply adjusting the ambient temperature.

3.3. Crystalline Structure of SF Mats. It has been reported that silk fibroin from the B. mori contains two forms of crystalline modifications, silk I and silk II, as well as the amorphous structure. Moreover, silk II is commonly considered to be constituted of $\beta$-sheets [28]. To further investigate the effects of water vapor annealing temperature and time on SF fibers, WAXD diffractograms (Figure 4) were obtained to analyze the crystalline structure of SF according to Asakura's assignments [29]. Regardless of the temperature, all samples posttreated for different times (Figure 4(a)) exhibit apparent diffraction peaks at $D$-spacing of $0.226,0.36,0.43 \mathrm{~nm}$ which correspond to the reflection of silk II structure [30, 31]. Meanwhile, the characteristic reflection of amorphous structure at $D$-spacing of $0.407 \mathrm{~nm}$ is observed in the as-spun fibers, while it is absent in water-vapor-annealed fibers. It indicates that the crystallization rate of SF during water vapor annealing at $65^{\circ} \mathrm{C}$ is quite rapid. This relationship can be seen more obviously from Figure 5(a). During water vapor annealing at $65^{\circ} \mathrm{C}$, the crystallinity of SF mats improves promptly from $35.5 \%$ to $47.3 \%$ within $1 \mathrm{~h}$. However, when the annealing time prolongs from 1 to $24 \mathrm{~h}$, the crystallinity keeps improving gradually and further reaches $52.2 \%$. It can be concluded that time is an important factor to control the crystallization of SF mats during water vapor annealing and the rise of annealing time leads to a higher crystallinity. Nevertheless, the influence of time is rather limited, especially under a high ambient temperature.

Figure 4(b) shows the influence of temperature on SF mats during water vapor annealing. When the annealing time was fixed at $3 \mathrm{~h}$, the characteristic reflection of silk I structure at $D$-spacing of $0.72 \mathrm{~nm}[32,33]$ can be observed on the diffractograms at 45 and $55^{\circ} \mathrm{C}$. At higher temperatures of 65 and $75^{\circ} \mathrm{C}$, clear changes of the diffractograms occur. Not only silk I reflection at $0.72 \mathrm{~nm}$ disappears, but also silk II reflections become more intense with the increasing annealing temperature. It can be found from Figure 5(b) that the crystallinity of SF mats increases almost linearly from $45.1 \%$ to $51.5 \%$ with raising temperature from 45 to $75^{\circ} \mathrm{C}$. The above results suggest that the temperature in water vapor annealing process could significantly influence the crystallization behavior of SF mats. 


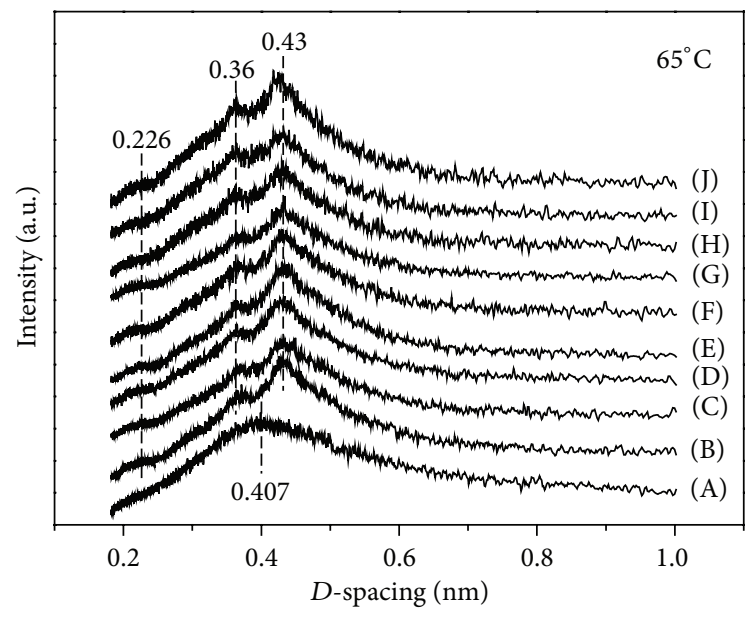

(a)

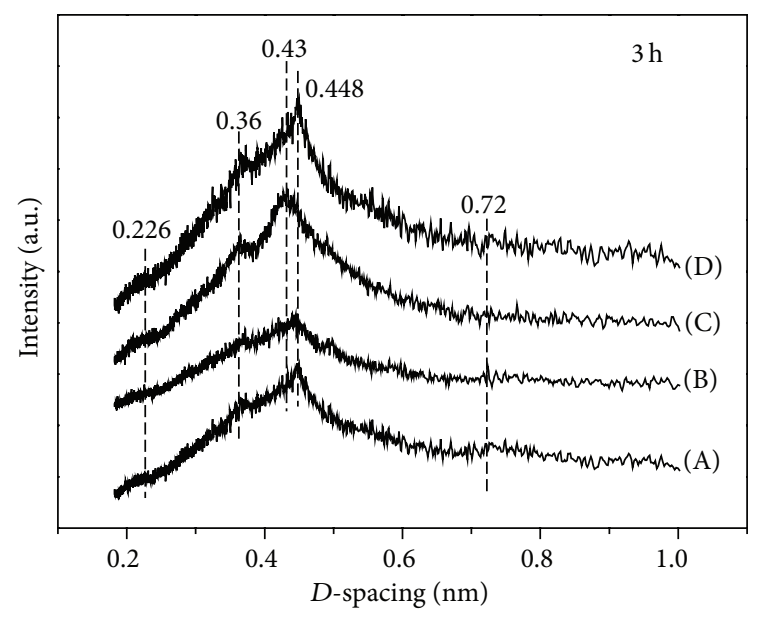

(b)

FiguRE 4: WAXD diffractograms of electrospun RSF fibers: (a) samples treated with water vapor at $65^{\circ} \mathrm{C}$ for different times: (A) as-spun, (B) $0.5 \mathrm{~h},(\mathrm{C}) 1 \mathrm{~h},(\mathrm{D}) 3 \mathrm{~h},(\mathrm{E}) 6 \mathrm{~h},(\mathrm{~F}) 9 \mathrm{~h},(\mathrm{G}) 12 \mathrm{~h},(\mathrm{H}) 15 \mathrm{~h},(\mathrm{I}) 18 \mathrm{~h}$, and (J) $24 \mathrm{~h}$; (b) samples treated with water vapor for $3 \mathrm{~h}$ at different temperatures: (A) $45^{\circ} \mathrm{C}$, (B) $55^{\circ} \mathrm{C},(\mathrm{C}) 65^{\circ} \mathrm{C}$, and (D) $75^{\circ} \mathrm{C}$.

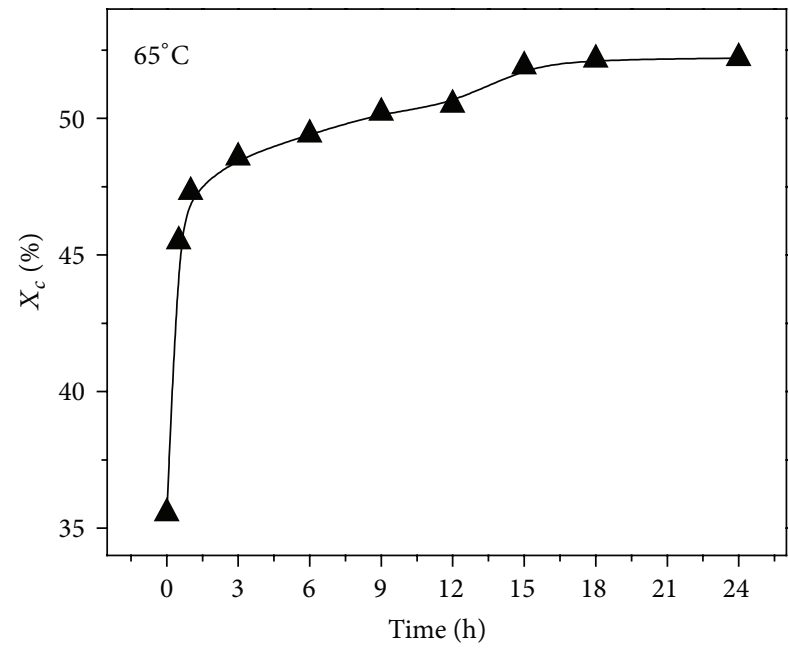

(a)

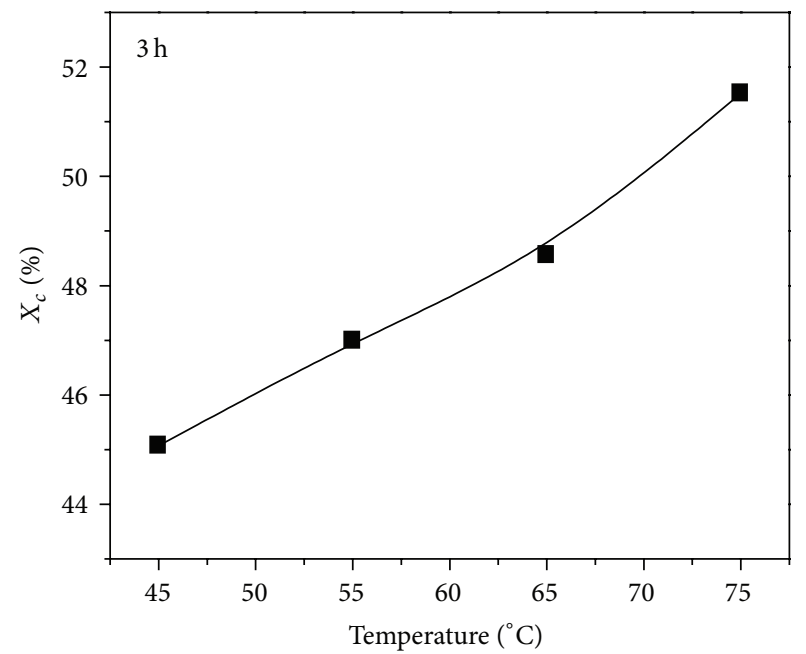

(b)

FIGURE 5: Crystallinities of electrospun RSF mats treated with water vapor: (a) at $65^{\circ} \mathrm{C}$ for different times; (b) for $3 \mathrm{~h}$ at different temperatures.

3.4. Mechanical Properties of SF Mats. The mechanical properties of the SF mats treated with water vapor at different temperatures and times are shown in Figure 6. It can be seen from Figure 6(a) that the breaking strength of the SF mats is greatly improved after annealing in water vapor at $65^{\circ} \mathrm{C}$ and gradually increases with prolonged treating time. When temperature rises, a more significant increasing trend of breaking strength can be found in Figure 6(b). The two curves of breaking strength in Figure 6 present great consistency with the corresponding crystallinity changes shown in Figure 5. This indicates that the potential SF materials with tunable properties and structures can be achieved by controlling the annealing time and temperature. Although the water-vapor- annealed SF mats do not have mechanical properties comparable to those of the posttreated mats via uniaxial drawing in ethanol solution [20], the moderate characteristic of water vapor annealing is still quite attractive. The mild conditions would be favorable for drug loading and preparation of SF materials with enhanced and uniform mechanical properties [34]. When the mats are annealed at $65^{\circ} \mathrm{C}$ for $15 \mathrm{~h}$, the breaking stress is improved to $6.0 \mathrm{MPa}$, which is about 4 times of the as-spun mats (1.8 MPa) [20]. The mats with similar properties could also be achieved within $3 \mathrm{~h}$ while raising the temperature to $75^{\circ} \mathrm{C}$. This well exhibits the time-temperature equivalence, which may be attributed to the more energy that SF molecules absorbed for conformational transition in a longer annealing period or at a higher annealing temperature. From another aspect, 


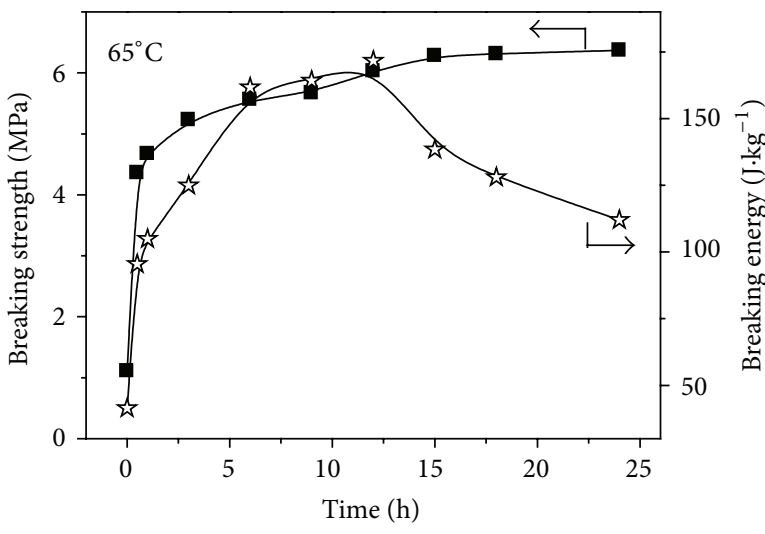

(a)

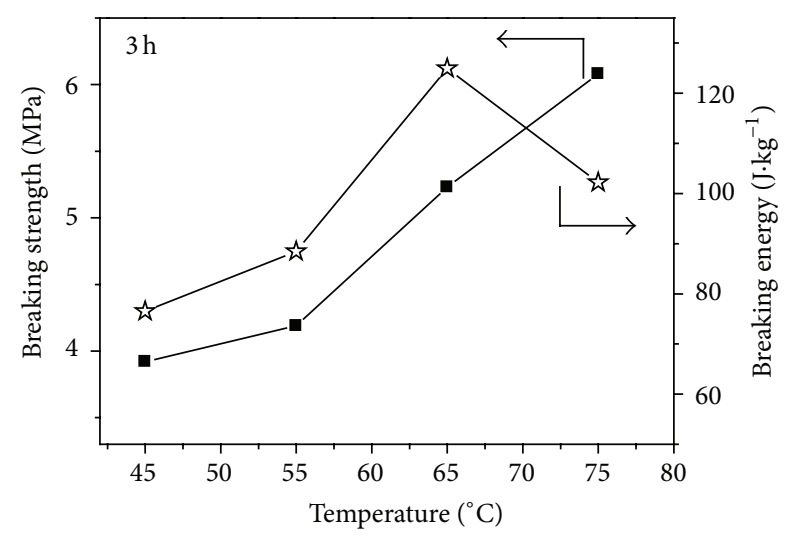

(b)

FIGURE 6: Breaking strength and breaking energy of electrospun RSF mats treated with water vapor: (a) at $65^{\circ} \mathrm{C}$ for different times; (b) for $3 \mathrm{~h}$ at different temperatures.

the motion of SF molecules is time dependent. The longer time could result in a more complete structure transition, namely, an increased content of the stable $\beta$-sheet structure in SF.

However, the breaking energy of the mats changes irregularly with annealing condition. It increases with annealing time or temperature first but decreases at an annealing time longer than $15 \mathrm{~h}$ in Figure 6(a) or at a temperature higher than $65^{\circ} \mathrm{C}$ in Figure 6(b). This may be attributed to the microstructure changes in SF fibers. With increasing treating time or temperature, the transformation from silk I to silk II is performed more completely. As the primary antiparallel $\beta$-sheet structure in silk II structure is more stable than the characterized $\beta$-turn type in silk I [35], the SF mats present a higher breaking elongation with increasing $\beta$-sheet content. When the crystallinity of SF mats is higher than $50 \%$, the samples with low breaking strain become much brittle and the breaking energy decreases. This phenomenon is similar to the results of SF films [18].

\section{Conclusions}

An effective and easy-conducting approach was developed to fabricate regenerated SF mats through water vapor annealing under different conditions of time and temperature. Water vapor can effectively induce the conformational transition of SF from random coil $/ \alpha$-helix (silk I) to stable $\beta$-sheet (silk II) conformation and enhance the mechanical properties of the mats. The structures and properties of the SF mats significantly depend on the annealing time and temperature. Through improving the annealing temperature or prolonging the annealing time, we could achieve SF mats with tunable structures and enhanced mechanical properties. This waterbased posttreatment provides a potential option to adjust the secondary structure and crystallinity of SF mats in mild conditions, thereby controlling the properties of SF mats for specific applications without using harmful chemicals. The water-vapor-annealed SF mats and other silk-based materials could be the promising candidates in biomedical fields, including drug delivery, wound dressing, and tissue engineering.

\section{Conflict of Interests}

The authors declare that there is no conflict of interests regarding the publication of this paper.

\section{Acknowledgments}

This work is supported by the National Natural Science Foundation of China (21274018, 81170641), the Shanghai Rising Star Program (12QA1400100), the Innovation Program of the Shanghai Municipal Education Commission (12ZZ065), DHU Distinguished Young Professor Program (A201302), and the Fundamental Research Funds for the Central Universities.

\section{References}

[1] D. L. Kaplan, "Silk polymers," in Workshop on Silks: Biology, Structure, Properties, Genetics, American Chemical Society, 1994.

[2] S. Mobini, B. Hoyer, M. Solati-Hashjin et al., "Fabrication and characterization of regenerated silk scaffolds reinforced with natural silk fibers for bone tissue engineering," Journal of Biomedical Materials Research A, vol. 101, no. 8, pp. 2392-2404, 2013.

[3] A. Seth, Y. G. Chung, E. S. Gil et al., "The performance of silk scaffolds in a rat model of augmentation cystoplasty," Biomaterials, vol. 34, no. 20, pp. 4758-4765, 2013.

[4] T. Wang, L. 1. Zhang, and X. j. He, "Preparation and characterization of a novel hybrid hydrogel composed of Bombyx mori fibroin and poly (n-isopropylacrylamide)," Journal of Nanomaterials, vol. 2013, Article ID 832710, 9 pages, 2013.

[5] T. Zhong, Z. Xie, C. Deng, M. Chen, Y. Gao, and B. Zuo, "Copolymer-induced silk-based hydrogel with porous and nanofibrous structure," Journal of Applied Polymer Science, vol. 127, no. 3, pp. 2019-2024, 2013. 
[6] A. Sionkowska and A. Płanecka, "Preparation and characterization of silk fibroin/chitosan composite sponges for tissue engineering," Journal of Molecular Liquids, vol. 178, pp. 5-14, 2013.

[7] B. Marelli, A. Alessandrino, S. Farè, G. Freddi, D. Mantovani, and M. C. Tanzi, "Compliant electrospun silk fibroin tubes for small vessel bypass grafting," Acta Biomaterialia, vol. 6, no. 10, pp. 4019-4026, 2010.

[8] X. Wang, E. Wenk, X. Zhang, L. Meinel, G. Vunjak-Novakovic, and D. L. Kaplan, "Growth factor gradients via microsphere delivery in biopolymer scaffolds for osteochondral tissue engineering," Journal of Controlled Release, vol. 134, no. 2, pp. 81-90, 2009.

[9] Z. Zhu, Y. Kikuchi, K. Kojima et al., "Mechanical properties of regenerated bombyx mori silk fibers and recombinant silk fibers produced by transgenic silkworms," Journal of Biomaterials Science, Polymer Edition, vol. 21, no. 3, pp. 395-411, 2010.

[10] Z. H. Zhu, K. Ohgo, and T. Asakura, "Preparation and characterization of regenerated Bombyx mori silk fibroin fiber with high strength," Express Polymer Letters, vol. 2, no. 12, pp. 885$889,2008$.

[11] X. Zhang, M. R. Reagan, and D. L. Kaplan, "Electrospun silk biomaterial scaffolds for regenerative medicine," Advanced Drug Delivery Reviews, vol. 61, no. 12, pp. 988-1006, 2009.

[12] B. M. Min, G. Lee, S. H. Kim, Y. S. Nam, T. S. Lee, and W. H. Park, "Electrospinning of silk fibroin nanofibers and its effect on the adhesion and spreading of normal human keratinocytes and fibroblasts in vitro," Biomaterials, vol. 25, no. 7-8, pp. 12891297, 2004.

[13] G. M. Nogueira, A. C. D. Rodas, C. A. P. Leite et al., "Preparation and characterization of ethanol-treated silk fibroin dense membranes for biomaterials application using waste silk fibers as raw material," Bioresource Technology, vol. 101, no. 21, pp. 8446-8451, 2010.

[14] A. L. Oliveira, L. Sun, H. J. Kim et al., "Aligned silk-based 3-D architectures for contact guidance in tissue engineering," Acta Biomaterialia, vol. 8, no. 4, pp. 1530-1542, 2012.

[15] L. Fan, H. Wang, K. Zhang, C. He, Z. Cai, and X. Mo, "Regenerated silk fibroin nanofibrous matrices treated with 75\% ethanol vapor for tissue-engineering applications," Journal of Biomaterials Science, Polymer Edition, vol. 23, no. 1-4, pp. 497508, 2012.

[16] B. M. Min, L. Jeong, K. Y. Lee, and W. H. Park, "Regenerated silk fibroin nanofibers: water vapor-induced structural changes and their effects on the behavior of normal human cells," Macromolecular Bioscience, vol. 6, no. 4, pp. 285-292, 2006.

[17] L. Jeong, K. Y. Lee, J. W. Liu, and W. H. Park, “Time-resolved structural investigation of regenerated silk fibroin nanofibers treated with solvent vapor," International Journal of Biological Macromolecules, vol. 38, no. 2, pp. 140-144, 2006.

[18] X. Hu, K. Shmelev, L. Sun et al., "Regulation of silk material structure by temperature-controlled water vapor annealing," Biomacromolecules, vol. 12, no. 5, pp. 1686-1696, 2011.

[19] Y. Hang, Y. Zhang, Y. Jin, H. Shao, and X. Hu, "Preparation and characterization of electrospun silk fibroin/sericin blend fibers," Journal of Materials Research, vol. 26, no. 23, pp. 2931-2937, 2011.

[20] S. Fan, Y. Zhang, H. Shao, and X. Hu, "Electrospun regenerated silk fibroin mats with enhanced mechanical properties," International Journal of Biological Macromolecules, vol. 56, pp. 83-88, 2013.

[21] H. Pan, Y. Zhang, Y. Hang et al., "Significantly reinforced composite fibers electrospun from silk fibroin/carbon nanotube aqueous solutions," Biomacromolecules, vol. 13, no. 9, pp. 28592867, 2012.

[22] W. Wei, Y. Zhang, Y. Zhao, H. Shao, and X. Hu, "Studies on the post-treatment of the dry-spun fibers from regenerated silk fibroin solution: Post-treatment agent and method," Materials and Design, vol. 36, pp. 816-822, 2012.

[23] M. E. Rousseau, T. Lefèvre, L. Beaulieu, T. Asakura, and M. Pézolet, "Study of protein conformation and orientation in silkworm and spider silk fibers using Raman microspectroscopy," Biomacromolecules, vol. 5, no. 6, pp. 2247-2257, 2004.

[24] B. G. Frushour and J. L. Koenig, "Raman spectroscopic study of poly ( $\beta$ benzyl-L-aspartate) and sequential polypeptides," Biopolymers, vol. 14, no. 10, pp. 2115-2135, 1975.

[25] X. Hu, D. Kaplan, and P. Cebe, "Dynamic protein-water relationships during $\beta$-sheet formation," Macromolecules, vol. 41, no. 11, pp. 3939-3948, 2008.

[26] X. Hu, D. Kaplan, and P. Cebe, "Effect of water on the thermal properties of silk fibroin," Thermochimica Acta, vol. 461, no. 1-2, pp. 137-144, 2007.

[27] C. Mo, P. Wu, X. Chen, and Z. Shao, "The effect of water on the conformation transition of Bombyx mori silk fibroin," Vibrational Spectroscopy, vol. 51, no. 1, pp. 105-109, 2009.

[28] R. Fraser, Conformation in Fibrous Proteins and Related Synthetic Polypeptides, Elsevier Science, Amsterdam, The Netherlands, 2012.

[29] T. Asakura, A. Kuzuhara, R. Tabeta, and H. Saitô, "Conformation characterization of Bombyx mori silk fibroin in the solid state by high-frequency $13 \mathrm{C}$ cross polarization-magic angle spinning NMR, x-ray diffraction, and infrared spectroscopy," Macromolecules, vol. 18, no. 10, pp. 1841-1845, 1985.

[30] L. F. Drummy, D. M. Phillips, M. O. Stone, B. L. Farmer, and R. J. Naik, "Thermally induced $\alpha$-helix to $\beta$-sheet transition in renegated silk fibers and films," Biomacromolecules, vol. 6, no. 6, pp. 3328-3333, 2005.

[31] S. W. Ha, Y. H. Park, and S. M. Hudson, "Dissolution of bombyx mori silk fibroin in the calcium nitrate tetrahydratemethanol system and aspects of wet spinning of fibroin solution," Biomacromolecules, vol. 4, no. 3, pp. 488-496, 2003.

[32] O. Kratky, E. Schauenstein, and A. Sekora, "An unstable lattice in silk fibroin," Nature, vol. 165, no. 4191, pp. 319-320, 1950.

[33] B. Lotz and H. D. Keith, "Crystal structure of poly(l-Ala-Gly)II. A model for silk I," Journal of Molecular Biology, vol. 61, no. 1, pp. 201-215, 1971.

[34] B. Kundu, R. Rajkhowa, S. C. Kundu, and X. Wang, "Silk fibroin biomaterials for tissue regenerations," Advanced Drug Delivery Reviews, vol. 65, no. 4, pp. 457-470, 2013.

[35] J. Ashida, K. Ohgo, K. Komatsu, A. Kubota, and T. Asakura, "Determination of the torsion angles of alanine and glycine residues of model compounds of spider silk (AGG)10 using solid-state NMR methods," Journal of Biomolecular NMR, vol. 25, no. 2, pp. 91-103, 2003. 

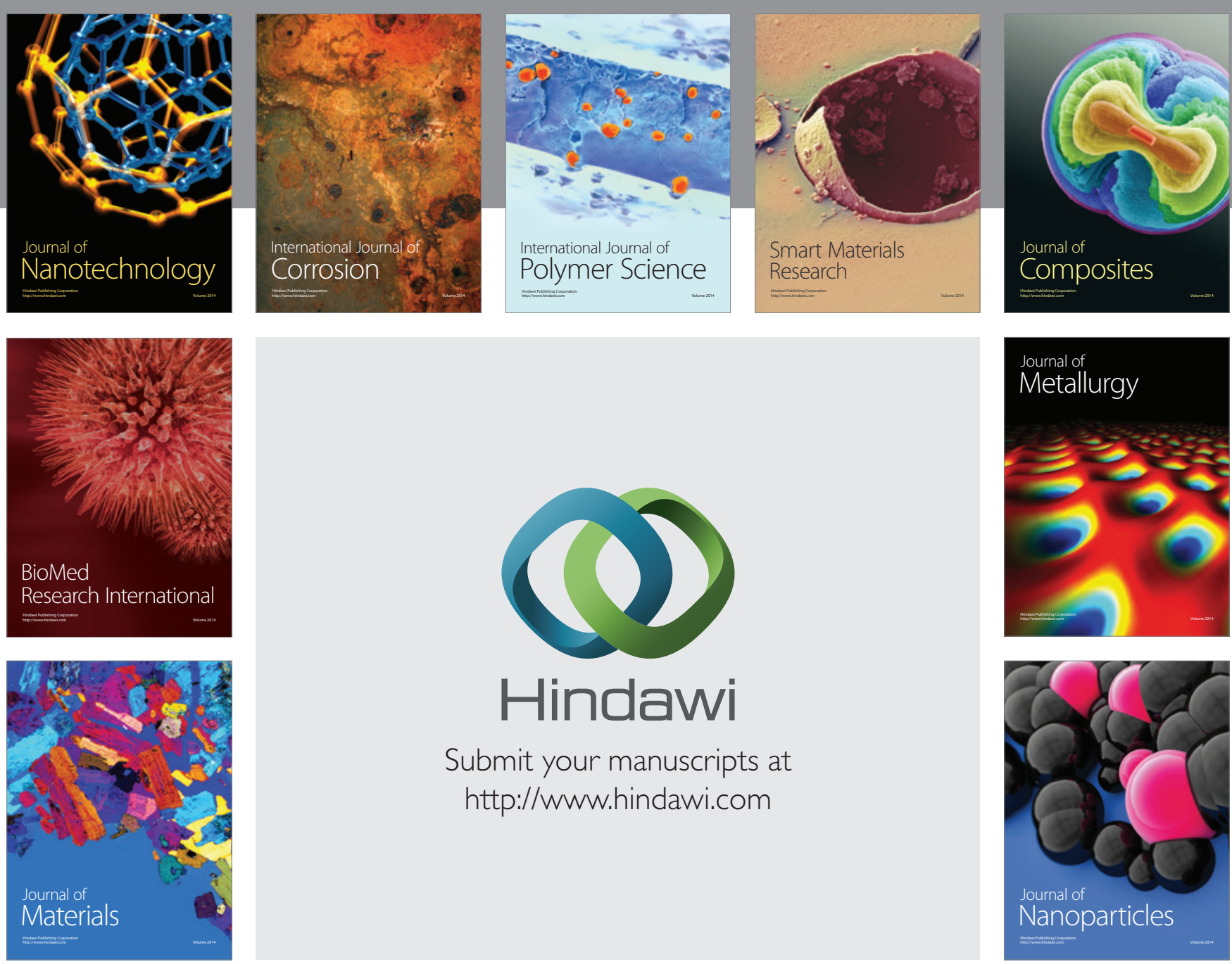

Submit your manuscripts at http://www.hindawi.com
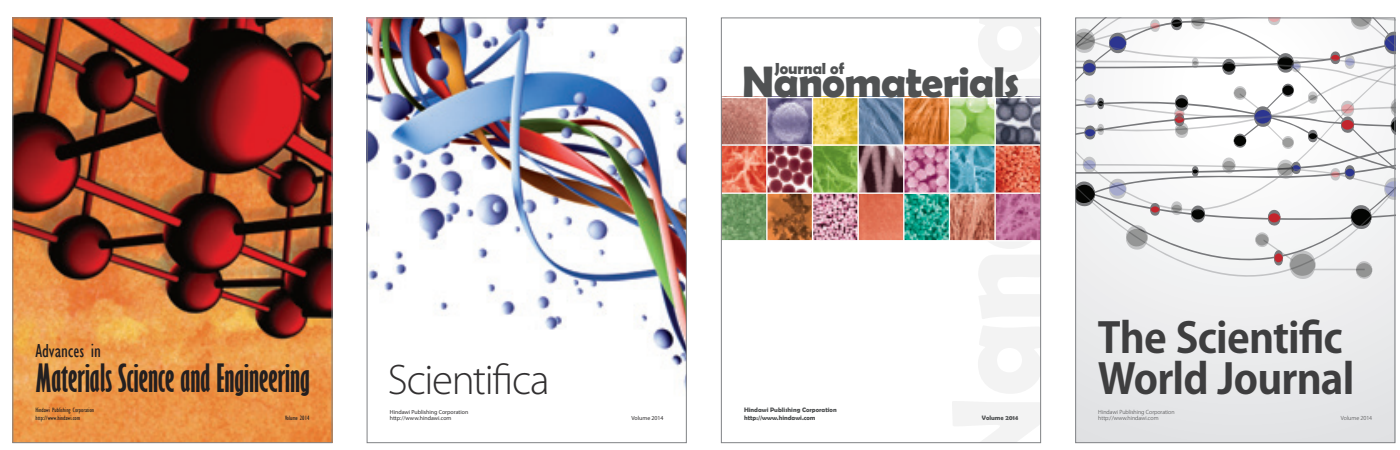

\section{The Scientific World Journal}
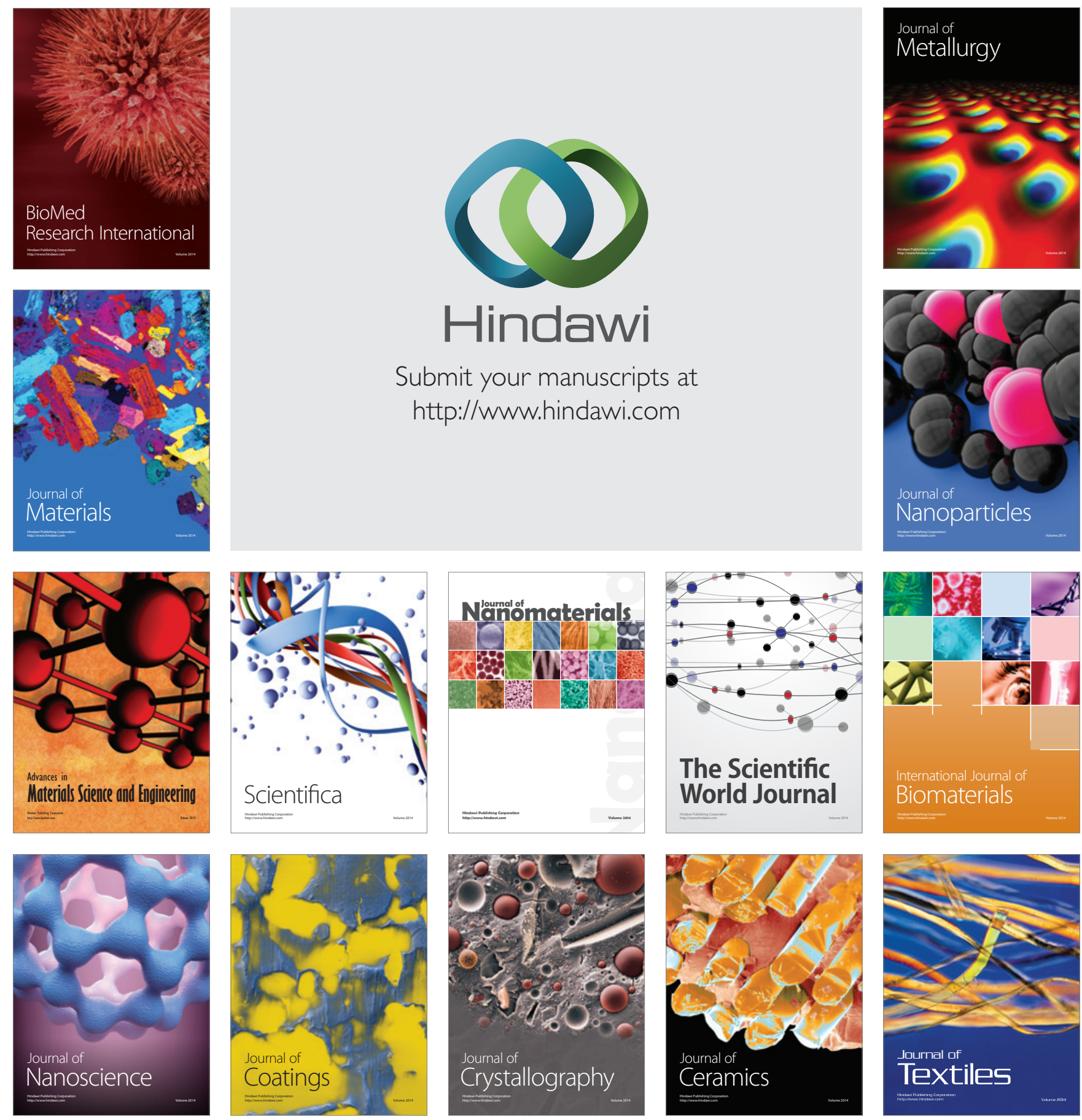